\title{
Polypharmacy in Primary Care Practices among Chronic Elderly Patients in Gaza Strip
}

\author{
Mahmoud Taleb1', Abed Al-Kareem Abed², Abedel Rahman Dahudi'3 , Ahmed Najim4", \\ Adham Ahmed ${ }^{4}$ \\ ${ }^{1}$ Faculty of Pharmacy, Alazhar University, Gaza, Palestine \\ ${ }^{2}$ Medical Services, Gaza, Palestine \\ ${ }^{3}$ Palestinian Ministry of Health, Gaza, Palestine \\ ${ }^{4}$ Faculty of Intermediate Studies, University of Palestine, Gaza, Palestine \\ Email: a.najem@up.edu.ps
}

Received 15 January 2014; revised 18 February 2014; accepted 12 March 2014

Copyright (C) 2014 by authors and Scientific Research Publishing Inc.

This work is licensed under the Creative Commons Attribution International License (CC BY). http://creativecommons.org/licenses/by/4.0/

(c) $\underset{\mathrm{EY}}{0}$ Open Access

\section{Abstract}

Introduction: The increasing number of elderly, and drug use among the elderly, emphasizes the need for continuous monitoring of drug utilization. Chronic diseases are frequent among the older population; the rate of drug related problems and drug-drug interactions (DDIs) with the medical and financial consequences are enormous. Polypharmacy (PP) is defined as the concomitant use of 5 or more medications. We studied PP among chronic elderly patients in Gaza Strip and its distribution among primary health care clinics in different areas. Materials and Methods: This study is a descriptive analytical study, analyzing prescription data from general practices during a 3-month time period, to measure the prevalence of $P P$ and medication errors among chronic elderly patients. Data were collected directly from the prescriptions and medical records, which contain personal data for patients like patient age and gender, included the current illness, drug treatment for the current illness, chronic disease/s and drug treatment for chronic disease/s. SPSS software was used to analyze the obtained data. Results: Percent of major PP was the highest among patients aged 60 - 69 years when compared with other ages categories of study population but not reached to be statisticaly significant (0.012). Major PP was higher in female patients than that in male patients but difference wasn't statistically significant $(0.5)$. The average number of drug per prescription was $3.4 \mathrm{drug}$; and the minimum value per prescription was 1 meanwhile maximum value was 9 ( $\mathrm{SD} \pm 1.7$ ). Conclusion: $\mathrm{PP}$ (use of five drugs or more) is more prevalent among elderly patients with multiple diseases. Female patients consume more drugs than male do. There were some regional differences in drug utilization not explained by morbidity, suggesting some variations in prescribing behaviors. 
Keywords

Polypharmacy; Elderly; Gaza Strip; Chronic Diseases; Primary Health Care

\section{Introduction}

Escalating pharmaceutical costs, new budgetary demands and growing awareness of health risks for patients with Polypharmacy (PP) exert pressure on General Practitioners (GPs) to reduce medication. This necessitates a good understanding of how multiple drug use comes about. There are two common definitions of PP available. It is determined either as the simultaneous use of certain number of medications (5 or more) [1]-[3] or as unnecessary overuse of drugs [4]. It can refer to perceptions of prescribers or consumers and may or may not include over-the-counter (OTC) remedies. If defined as use of five or more drugs, between $4 \%$ [1] and 34\% [5] of people aged 65 years and above are affected by PP. A number of studies investigated determinants of prescribed PP and reported relevant socio-demographic factors (age, gender, education, employment and socio-economic status) [5]-[7], influence of disease (multimorbidity, multiple complaints, well-being and chronic illness) [8] [9] and health system factors (prescriber related, perceived patient pressure and free access to medications) [10][13].

Rational use of medicines is a crucial part of the national health policy and access to medicines is one of the vital tools needed to improve and maintain health. Irrational use of medicines is now a worldwide problem, which has a serious impact on health and economy that may result in wastage of resources, inappropriate patient demand, serious adverse drug reactions, increase antimicrobial resistance, increase drug-related morbidity and mortality. World Health Organization (WHO) has reported that more than $50 \%$ of national and $60 \%-80 \%$ of individual health care expenditure is spent on medicines [14].

Safe and effective pharmacotherapy remains one of the greatest challenges in geriatric medicine. Ageing alters the pharmacokinetics and pharmacodynamics of many drugs. In addition, pharmacotherapy may be complicated by difficulties with obtaining drugs or complying with drug regimens [15]. New drugs continuously develop leading to more and more possibilities of medication use, for indications previously thought to be resistant to pharmacotherapy, adding to the problems faced by elderly because of drug-disease, drug-drug interactions. Many diseases of the elderly, such as hypertension, are now treated more actively than before, and the threshold of starting medication has become lower. With advancing age, a greater share of individuals becomes susceptible to chronic morbidity which requires long-term medical treatment and leads to the use of several medications [16]. Health care professionals are responsible to ensure safe dispensing and use of drug regimens involving the use of drug combinations that may interact and cause serious adverse events [17]. The main objective of our study was to measure the prevalence of PP and medication errors among chronic elderly patients.

\section{Methods}

This study is a descriptive analytical study, analyzing prescription data from general practices during a 3-month time period, to measure the prevalence of PP and medication errors among chronic elderly patients. This design was chosen because it is the best design to describe the drugs situation in governmental PHC centers. It is less expensive and enables the researcher to meet the study objective in a short time. It also studies the cause and effect at the same point of time and thus provides some possible indication about causation relationships [18].

\subsection{Population and Sample Size}

Our target population is elderly patients from both genders (males and females) with chronic disease/s who attend the primary health care clinics - Gaza Strip-Palestine, but the direct study populations were the prescriptions and the patient's files, where they conducted all research objectives. The sample size was 360 subjects of chronic elderly patients from both genders.

Six primary health care clinics representing all Gaza Strip governorates were participating in the study, in which each governorate was represented by the main central clinic in this governorate. Sixty chronic elderly patients were selected randomly from each clinic. However, 9 of the collected sample were missed, so the real 
sample size was 351 .

\subsection{Data Collection}

Data was collected directly from the prescriptions and medical records, which contain personal data for patients like patient age and gender, included the current illness, drug treatment for the current illness, chronic disease/s and drug treatment for chronic disease/s.

\subsubsection{Prescribing Indicators of Drugs}

Interested by prescribing pattern; and includes:

- Average number of drugs per prescription = total number of drugs prescribed/total number of prescriptions surveyed;

- Percentage of prescriptions with an antibiotic prescribed $=$ (number of prescriptions during which an antibiotic was prescribed/total number of prescriptions surveyed $) \times 100$;

- Percentage of prescriptions with an analgesic prescribed = (number of prescriptions during which an analgesic was prescribed/total number of prescriptions surveyed) $\times 100$;

- Age was distributed into intervals; 60 - 70, 71 - 80, 80+.

- Drug use and PP:

PP was defined as concomitant use of five or more prescription medications [8]. We adopted the World Health Organization definition of PP; which was the concomitant use of five or more drugs [19].

\subsection{Statistical Analysis}

The data was analyzed using Statistical package for social sciences (SPSS version 13). We started by frequency of the different variables. Cross tabulation for specific study variables and advanced statistical analysis was used to explore the potential relationship between the study variables, including: One way ANOVA test and Chi Square test. $\mathrm{P}$ value equal or less than 0.05 was considered statistically significant, with confidence interval (CI) of $95 \%$.

\section{Results}

\subsection{Characteristics of the Samples}

The data collected showed that $59.8 \%$ of the study sample was aged 60 - 69 years, 30.8\% was aged 70 - 79 years, while $9.4 \%$ of the study population was aged 80 years or over. The mean ages were (68.86) years (SD \pm 7.1 ). Also shows that $54.1 \%$ of the study sample was females, and $45.9 \%$ were males as shown in Table 1.

Figure 1 shows that 229 patients (65.2\%) have hypertension (HTN), 168 patients (47.9\%) have Diabetes Mellitus (DM), 78 patients (22.2\%) have cardiovascular disease (CVD), and 33 patients (9.4\%) have other diseases which include bronchial asthma, thyroid dysfunction, dyslipidemia, gout, renal failure, and glaucoma.

\begin{tabular}{|c|c|}
\hline \multicolumn{2}{|c|}{ Characteristics of the Samples } \\
\hline Age (Years) & Percent \\
\hline $60-69$ & $59.8 \%$ \\
\hline $70-79$ & $30.8 \%$ \\
\hline+80 & $9.4 \%$ \\
\hline Gender & Percent \\
\hline Male & $45.9 \%$ \\
\hline Female & $54.1 \%$ \\
\hline
\end{tabular}




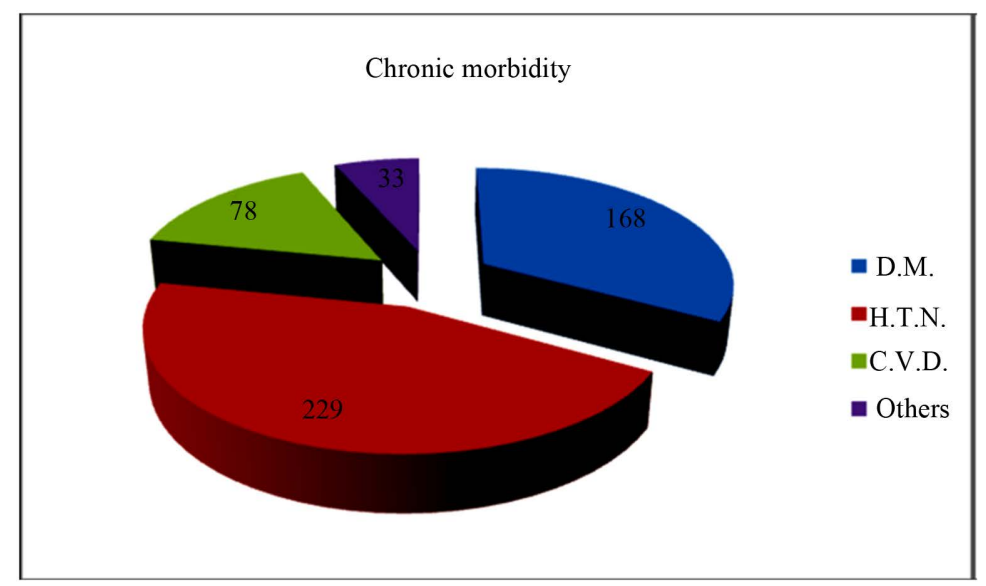

Figure 1. Chronic morbidity of the study population.

\subsection{Relationship between Polypharmacy, Age and Gender}

Table 2 shows percent of major PP was the highest among patients aged 60 - 69 years when compared with other ages categories of study population but not reached to be statistical significant (0.012). Major PP was higher in female patients than male but also difference wasn't statistically significant (0.5).

\subsection{Drug Prescription}

In Table 3, the average number of drug per prescription was 3.4 drug; and the minimum value per prescription was 1 meanwhile maximum value was $9(\mathrm{SD} \pm 1.7)$. When this indicator was studied by different governorates, mean number of drug per prescription ranged from 2.8 to 4 among governorates. It was expected that difference refers to different physician attitude and behavior with socio economical culture variation among different governorates.

The majority of patients were taking a cardiovascular drug. The most common drug groups were ACE-inhibitors (39.3\%), followed by antiplatelets (37.3\%), lipid lowering drugs (statins) (31.9\%), beta blocking (18.1), Ca blocker (19.2), nitrates (16.1) and diuretics (22.6). The most common main therapeutic drugs are presented in Table 4.

\section{Discussion}

\subsection{Polypharmacy with Age}

Studies of PP in the population have shown that PP is most frequently observed among elderly people [20]. In our study, the prevalence of PP was $27.6 \%$ with age group $60-69$ and $25.9 \%$ with the age group of $70-79$ years, while this percent declines to $18.2 \%$ among elderly patients aged 80 years or more. The prevalence of PP among very old individuals ( $>80$ years of age) was somewhat lower than among the elderly in general. Similarly, Helling et al. found that the mean number of prescription drugs increased with age until the age of 85 years for women, and the age of 80 years for men, after which the mean number of prescription drugs decreased [21]. Also it was found a reduced prevalence of major PP among very old individuals [22].

\subsection{Gender Differences}

A higher prevalence of drug use among women was found in this study and a similar trend was observed for PP. The prevalence of PP between females (27.9\%) was higher than males (24.2\%), although it was not statistically significant. Among the elderly, however, there were no differences between the sexes in the prevalence of PP. This is in accordance with Nolan and O'Malley's studies of age-related prescription patterns in general practice [23] [24]. They found a steady increase in the proportion of men taking prescription drugs, while the prescribing rates for women decreased from the age of 70 years, and from this age there was no significant difference between males and females. 
Table 2. Relationship between polypharmacy, age and gender.

\begin{tabular}{cccccc}
\hline \multirow{2}{*}{ Variable } & Less than 2 drugs & \multicolumn{2}{c}{ Polypharmacy } & \multirow{2}{*}{ Total } & P Value \\
\cline { 3 - 4 } & & Minor (2 - 4 drugs) & Major (5 or more) & & \\
\hline & & Age (Years) & & & \\
$70-69$ & $17(8.1 \%)$ & $135(64.3 \%)$ & $58(27.6 \%)$ & 210 & \\
$\geq 80$ & $23(21.3 \%)$ & $57(52.8 \%)$ & $28(25.9 \%)$ & 108 & $\mathbf{0 . 0 1 2}$ \\
Total & $6(18.2 \%)$ & $21(63.6 \%)$ & $6(18.2 \%)$ & 33 & \\
& $46(13.1)$ & $213(60.7 \%)$ & $92(26.2 \%)$ & 351 & \\
Male & $24(14.9 \%)$ & Gender & & & \\
Female & $22(11.6 \%)$ & $115(60.5 \%)$ & $53(27.9 \%)$ & 190 & $\mathbf{0 . 5}$ \\
Total & $46(13.1 \%)$ & $213(60.7 \%)$ & $92(26.2 \%)$ & 351 & \\
\hline
\end{tabular}

Table 3. Patient age and total number of drugs, prescribed by the patient's general practitioner.

\begin{tabular}{|cccccc}
\hline \multicolumn{2}{c}{ Age (Years) } & $\mathbf{6 0 - 6 9}$ & $\mathbf{7 0 - 7 9}$ & $\mathbf{2 8 0}$ & Total \\
\hline & $\mathbf{1}$ & $17(8.1 \%)$ & $23(21.3 \%)$ & $6(18.2 \%)$ & 46 \\
& $\mathbf{2}$ & $45(21.4 \%)$ & $18(16.7 \%)$ & $5(15.2 \%)$ & 68 \\
Total no. & $\mathbf{3}$ & $49(23.3 \%)$ & $24(22.2 \%)$ & $8(24.2 \%)$ & 81 \\
of drugs & $\mathbf{5}$ & $41(19.5 \%)$ & $15(13.9 \%)$ & $8(24.2 \%)$ & 64 \\
& $\mathbf{6}$ & $26(12.4 \%)$ & $16(14.8 \%)$ & $5(15.2 \%)$ & 47 \\
& $\mathbf{7}$ & $5(2.4 \%)$ & $0(0 \%)$ & $0(0 \%)$ & 5 \\
& $\mathbf{8}$ & $4(1.9 \%)$ & $2(1.9 \%)$ & $0(0 \%)$ & 6 \\
& $\mathbf{9}$ & $1(0.5 \%)$ & $0(0 \%)$ & $0(0 \%)$ & 1 \\
Total & & $\mathbf{2 1 0}$ & $\mathbf{1 0 8}$ & $\mathbf{3 3}$ & $\mathbf{3 5 1}$ \\
\hline
\end{tabular}

Table 4. The 15 most common chronic medications prescribed.

\begin{tabular}{cc}
\hline Medication & Number of patients (\%) \\
Enalapril $20 \mathrm{mg}$ & $139(39.3 \%)$ \\
Aspirin $100 \mathrm{mg}$ & $132(37.3 \%)$ \\
Atorvastatin $20 \mathrm{mg}$ & $113(31.9 \%)$ \\
Glibenclamide $5 \mathrm{mg}$ & $95(26.8 \%)$ \\
Metformin $850 \mathrm{mg}$ & $91(25.4 \%)$ \\
Amlodipine $5 \mathrm{mg}$ & $68(19.2 \%)$ \\
Atenolol $100 \mathrm{mg}$ & $64(18.1 \%)$ \\
Furosemide $40 \mathrm{mg}$ & $63(17.8 \%)$ \\
Isosorbide Mononitrate 20, 40 mg & $57(16.1 \%)$ \\
Insulin Mixtard & $51(14.1 \%)$ \\
Carbamazepine $200 \mathrm{mg}$ & $22(6.2 \%)$ \\
Salbutamol $2 \mathrm{mg}$ & $14(3.9 \%)$ \\
Digoxin $0.25 \mathrm{mg}$ & $9(2.5 \%)$ \\
Hydrochlorothiazide $25 \mathrm{mg}$ & $9(2.5 \%)$ \\
Spironolactone $100 \mathrm{mg}$ & $8(2.3 \%)$ \\
\hline
\end{tabular}




\subsection{Health Problems}

We find that $65.5 \%$ of the study population chronically have hypertension, $47.9 \%$ of elderly have diabetes mellitus, while $22.2 \%$ have cardiac diseases, and 9.4\% have other chronic diseases. Our study’s findings are in accordance with the findings of the Palestinian Central Bureau of Statistics that found the most common disease affecting elderly is hypertension, follows diabetes mellitus, and finally heart diseases [25]. This goes along with a case-control study carried out in Israel where a geriatric palliative approach and methodology to combat the problem of PP was introduced, assessment of the case group showed $46 \%$ of the patients have hypertension, while $30 \%$ of the patients have diabetes mellitus [26]. This is quite logical as Palestinians and Israelis have a common environment that justifies the similarities in co-morbidities findings.

\subsection{Drug Prescription}

Only a few studies have focused on health problems as predictors of PP, and none of them have employed a sample of the general population as study base. In a study of drug use among patients at a nursing home, the risk of PP was found to be highest for patients with cardiovascular problems [27].

By examining the prevalence of PP for individuals treated for different health problems, we found that the most decisive predictor of major PP was the health problems that were being treated. Thus, drug users treated for cardiovascular diseases, DM and hypertension had a higher risk of major PP than drug users in general, where $44.9 \%$ of CVD patients, $32.1 \%$ of DM and $27.1 \%$ of hypertensive patients are exposed to PP. When focusing on major PP at different age groups. We find that cardiovascular drugs and analgesics were predominant among elderly exposed to PP.

\section{Conclusion}

PP (use of five drugs or more) is more prevalent among elderly patients with multiple diseases. Female patients consume more drugs than male do. There were some regional differences in drug utilization not explained by morbidity, suggesting some variations in prescribing behaviors. The three most commonly used main drug classes were in good agreement with the pattern of morbidity in old age: cardiovascular system drugs, antidiabetic drugs and analgesics.

\section{References}

[1] Veehof, L., Stewart, R.E. and Haaijer-Ruskamp, F.M. (2000) The Development of Polypharmacy. A Longitudinal Study. Family Practice, 17, 261-267. http://dx.doi.org/10.1093/fampra/17.3.261

[2] Kennerfalk, A., Ruigomez, A. and Wallander, M.A. (2002) Geriatric Drug Therapy and Healthcare Utilization in the United Kingdom. Annals of Pharmacotherapy, 36, 797-803. http://dx.doi.org/10.1345/aph.1A226

[3] Fialova, D., Topinkova, E. and Gambassi, G. (2005) Potentially Inappropriate Medication Use Among Elderly Home Care Patients in Europe. Journal of the American Medical Association, 293, 1348-1358. http://dx.doi.org/10.1001/jama.293.11.1348

[4] Avorn, J. (2004) Polypharmacy. A New Paradigm for Quality Drug Therapy and Healthcare Utilization among the Elderly. Annals of Pharmacotherapy, 35, 1004-1009.

[5] Barat, I, Andreasen, F. and Damsgaard, E. (2000) The Consumption of Drugs by 75-Year-Old Individuals Living in Their Own Homes. European Journal of Clinical Pharmacology, 56, 501-509. http://dx.doi.org/10.1007/s002280000157

[6] Perry, B. and Turner, L. (2001) Aprediction Model for Polypharmacy: Are Older, Educated Women More Susceptible to an Adverse Drug Event? Journal of Women Aging, 13, 39-51. http://dx.doi.org/10.1300/J074v13n04 04

[7] Odubanjo, E., Bennett, K. and Feely, J. (2004) Influence of Socioeconomic Status on the Quality of Prescribing in the Elderly. A population Based Study. British Journal of Clinical Pharmacology, 58, 496-502. http://dx.doi.org/10.1111/j.1365-2125.2004.02179.x

[8] Linjakumpu, T., Hartikainen, S., Klaukka, T., Veijola, J., Kivela”, S. and Isoaho, R. (2002) Use of Medications and Polypharmacy Are Increasing among the Elderly. Journal of Clinical Epidemiology, 55, 809-817. http://dx.doi.org/10.1016/S0895-4356(02)00411-0

[9] Al-Windi, A. (2005) Determinants of Medicine Use in a Swedish Primary Health Care Practice Population. Pharmacoepidemiology and Drug Safety, 14, 47-51. http://dx.doi.org/10.1002/pds.1047

[10] Bjerrum, L., Sogaard, J., Hallas, J. and Kragstrup, J. (1999) Polypharmacy in General Practice: Differences between 
Practitioners. British Medical Journal, 49, 195-198.

[11] Hessel, A., Gunzelmann, T., Geyer, M. and Brahler, E. (2000) Utilization of Medical Services and Medication Intake of Patients over 60 in Germany. Zeitschrift für Gerontologie und Geriatrie, 33, 289-299. http://dx.doi.org/10.1007/s003910070049

[12] Little, P., Dorward, M., Warner, G., Stephens, K., Senior, J. and Moore, M. (2004) Importance of Patient Pressure and Perceived Pressure and Perceived Medical Need for Investigations, Referral, and Prescribing in Primary Care: Nested Observational Study. British Medical Journal, 328, 444-447. http://dx.doi.org/10.1136/bmj.38013.644086.7C

[13] Perkins, A., Kroenke, K. and Unutzer, J. (2004) Common Co-Morbidity Scales Were Similar in Their Ability to Predict Health Care Costs and Mortality. Journal of Clinical Epidemiology, 57, 1040-1048. http://dx.doi.org/10.1016/j.jclinepi.2004.03.002

[14] WHO (2003) Medicines Strategy: Framework for Action in Essential Drugs and Medicines Policy 2000-2003. World Health Organization, Geneva, No. (WHO/EDM/2000.1).

[15] Wilkinson, G.R. (1997) The Effects of Diet, Aging and Disease-States on Presystemic Elimination and Oral Drug Bioavailability in Humans. Advanced Drug Delivery Reviews, 27, 129-159. http://dx.doi.org/10.1016/S0169-409X(97)00040-9

[16] (1997) Joint National Committee the Sixth Report of the Joint National Committee (JNC VI) on Prevention, Detection, Evaluation, and Treatment of High Blood Pressure. Archives of Internal Medicine, 157, 2413-2446.

[17] Tamblyn, R., Huang, A. and Perreault, R. (2003) The Medical Office of the 21st Century (MOXXI): Effectiveness of Computerized Decision-Making Support in Reducing Inappropriate Prescribing in Primary Care. Canadian Medical Association Journal, 169, 549-556.

[18] Burns, S. and Grove, K. (1997) The Practice of Nursing Research. W.B Saunders.

[19] WHO (1985) The Rational Use of Drugs: Report of the Conference of Experts. Geneva, World Health Organization, Geneva.

[20] Bjerrum, L., Rosholm, J.U. and Hallas, J. (1997) Methods for Estimating the Occurrence of Polypharmacy by Means of a Prescription Database. European Journal of Clinical Pharmacology, 53, 7-11. http://dx.doi.org/10.1007/s002280050329

[21] Helling, D.K., Lemke, J.H., Semla, T.P., Wallace, R.B., Lipson, D. P. and Cornoni-Huntley, J. (1987). Medication use characteristics in the elderly: The Iowa 65+ Rural Health Study. Journal of the American Geriatrics Society, 35, 4-12.

[22] Heerdink, E.R., Leufkens, H.G., Koppedraaijer, C. and Bakker, A. (1995) Information on Drug Use in the Elderly: A Comparison of Pharmacy, General-Practitioner and Patient Data. Pharmacy World and Science, 17, 20-24. http://dx.doi.org/10.1007/BF01875554

[23] Nolan, L. and O’Malley, K. (1987) Age-Related Prescribing Patterns in General Practice. Comprehensive Gerontology. Section A, 1, 97-101.

[24] Nolan, L. and O’Malley, K. (1988) Prescribing for the elderly: Part II. Prescribing Patterns: Differences Due to Age. Journal of the American Geriatrics Society, 36, 245-254.

[25] Population Reference Bureau (2007) World Population Data Sheet. Demographic Data and Estimates for the Countries and Regions of the World.

[26] Garfinkel, D., Zur-Gil, S. and Ben-Israel, J. (2007) The War against Polypharmacy: A New Cost-Effective Geriatric-Palliative Approach for Improving Drug Therapy in Disabled Elderly People. IMAJ, 9, 430-434.

[27] Kalchthaler, T., Coccaro, E. and Lichtiger, S. (1977) Incidence of Polypharmacy in a Long-Term Care Facility. Journal of the American Geriatrics Society, 25, 308-313. 